\title{
Anti-fibrotic effect of bovine colostrum in carbon tetrachloride-induced hepatic fibrosis
}

\section{Dong Hyun Sinn, Geum-Youn Gwak, Young Ju Kwon, Seung Woon Paik}

Department of Medicine, Samsung Medical Center, Sungkyunkwan University School of Medicine, Seoul, Korea

Received: April 24, 2017

Revised: May 12, 2017

Accepted: May 19, 2017

Corresponding author:

Geum-Youn Gwak

Department of Medicine,

Samsung Medical Center,

Sungkyunkwan University

School of Medicine, 81 Irwon-ro,

Gangnam-gu, Seoul 06351, Korea

Tel: +82-2-3410-3409

E-mail:gy.gwak@samsung.com
This is an Open Access article distributed under the terms of the Creative Commons Attribution Non-Commercial License (http:// creativecommons.org/licenses/ by-nc/4.0/).

\begin{abstract}
Purpose: To investigate the preventive effect of colostrum on hepatic fibrosis induced by carbon tetrachloride $\left(\mathrm{CCl}_{4}\right)$ in mice.

Methods: Seven-week-old male Balb/C mice were treated with $\mathrm{CCl}_{4}$ with or without a diet of bovine colostrum (BC) for 2 weeks. Hepatic fibrosis was determined using Sirius red staining, $\alpha$-smooth muscle actin ( $\alpha$-SMA) immunohistochemistry, immunoblot analysis, and quantitative polymerase chain reaction (PCR) for profibrogenic and proinflammatory genes. Hepatocellular injury was assessed through the measurement of serum alanine aminotransferase (ALT) levels.

Results: Compared to the $\mathrm{CCl}_{4}$ group, the $\mathrm{BC}+\mathrm{CCl}_{4}$ group had a $55 \%$ reduction in fibrosis as demonstrated by Sirius red staining. The $\mathrm{BC}+\mathrm{CCl}_{4}$ group also had a significant reduction in a-SMA expression according to immunohistochemistry and immunoblot. On quantitative $\mathrm{PCR}$, the $\mathrm{BC}+\mathrm{CCl}_{4}$ group showed significant 8.42-, 21.11-, 0.57-, and 2.90fold reductions in the expression of Acta2, Col1 $\alpha 1$, Tgf $\beta 1$, and Tnf- $\alpha$, respectively, compared to the $\mathrm{CCl}_{4}$ group. The serum ALT level was significantly reduced in the $\mathrm{BC}+\mathrm{CCl}_{4}$ group compared to the $\mathrm{CCl}_{4}$ group.

Conclusion: The present study demonstrated that $\mathrm{BC}$ ameliorated $\mathrm{CCl}_{4}$-induced hepatic fibrosis by inhibiting fibrogenesis-related gene expression and also decreased $\mathrm{CCl}_{4}$-induced hepatocyte injury. Therefore, BC might be therapeutically efficacious in preventing hepatic fibrosis in various liver diseases.
\end{abstract}

Keywords: Carbon tetrachloride; Colostrum; Fibrosis; Liver; Wounds and injuries

\section{INTRODUCTION}

Hepatic fibrosis is the result of chronic hepatocellular injury and the first step toward the development of devastating complications such as cirrhosis and hepatocellular carcinoma [1]. The process of hepatic fibrosis is considered to be reversible [2], and the blockade or reversal of hepatic fibrosis has become an important issue in medicine worldwide [3-5]. With advances in knowledge of hepatic fibrosis [6-9], considerable progress has been made in the development of novel drugs; however, most of these drugs are still under clinical trial, with uncertain efficacy and adverse events.

Colostrum is milk from lactating mammals that is secreted during the first approximately 72 
hours after birth. Colostrum differs from mature milk in that it contains abundant bioactive components, including growth factors, immunoglobulins, lactoperoxidase, lysozyme, lactoferrin, vitamins, peptides, and oligosaccharides, which are of great importance to human health $[10,11]$. Thus, colostrum has a variety of beneficial health effects such as bacteriostatic, bactericidal, anti-viral, anti-inflammatory, and immunomodulatory protection $[12,13]$, as well as high antioxidant capacity and radical scavenging activity $[14,15]$.

Oxidative stress is known to be a major contributing factor to the onset of hepatic fibrosis [16]. In pathologic conditions such as chronic hepatitis B virus (HBV) infection, alcoholic liver disease, and non-alcoholic fatty liver disease, the reactive oxygen species (ROS) generated within hepatocytes upregulate the expression of fibrosis-associated genes, which causes hepatic stellate cell (HSC) activation and collagen deposition. In an experimental setting, carbon tetrachloride $\left(\mathrm{CCl}_{4}\right)$ is able to induce hepatic fibrosis by stimulating the formation of free radicals, ROSs and lipid peroxidation products [17] and thus is widely used to generate hepatic fibrosis in model animals $[18,19]$.

This study was designed to investigate the preventive effect of colostrum on hepatic fibrosis induced by $\mathrm{CCl}_{4}$ in mice. The study provides a reliable experimental basis for the application of colostrum in the prevention and treatment of hepatic fibrosis.

\section{METHODS}

\section{Animals and experimental design}

Thirty male (aged 7 weeks) Balb/C mice were purchased from OrientBio (Seongnam, Korea). Following more than 7 days of acclimation, the mice were divided into four groups: the control group $(n=5)$ was fed with water $(15 \mu \mathrm{L} / \mathrm{g})$ five times a week and injected with corn oil $(2 \mu \mathrm{L} / \mathrm{g})$ twice a week intraperitoneally, the bovine colostrum $(B C)$ group $(n=5)$ was fed with $\mathrm{BC}(15 \mu \mathrm{L} / \mathrm{g})$ five times a week and injected with corn oil $(2 \mu \mathrm{L} / \mathrm{g})$ twice a week intraperitoneally, the $\mathrm{CCl}_{4}$ group $(n=10)$ was fed with water $(15 \mu \mathrm{L} / \mathrm{g})$ five times a week and injected with $\mathrm{CCl}_{4}$ (1:3 diluted in corn oil, $2 \mu \mathrm{L} / \mathrm{g}$ ) twice a week intraperitoneally, and the $\mathrm{BC}+\mathrm{CCl}_{4}$ group $(\mathrm{n}=10)$ was fed with $\mathrm{BC}(15 \mu \mathrm{L} / \mathrm{g})$ five times a week and injected with $\mathrm{CCl}_{4}(1: 3 \mathrm{di}-$ luted in corn oil, $2 \mu \mathrm{L} / \mathrm{g}$ ) twice a week intraperitoneally. The mice were treated for 2 weeks and sacrificed 48 hours after the final corn oil or $\mathrm{CCl}_{4}$ injection. When the mice were sacrificed, blood samples and livers were obtained. Blood samples were collected from the inferior vena cava (IVC), centrifuged, and stored at $-80^{\circ} \mathrm{C}$. All mice were given standard laboratory chow and water ad libitum and maintained under a 12-hour light/dark cycle. All animal experiments were performed according to the guidelines of the Center for Laboratory Animal Research of Samsung Medical Center and with the approval of the Institutional Animal Care and Use Committee of Samsung Medical Center (protocol number: 20140513001).

\section{Materials}

$\mathrm{BC}$ was purchased from Diatech Korea (Seoul, Korea). $\mathrm{CCl}_{4}$ and corn oil were purchased from Sigma (St. Louis, MO, USA).

\section{Measurements of serum alanine aminotransferase} Alanine aminotransferase (ALT) levels were measured with sera collected from the IVC using an FUJI DRI-CHEM SLIDE GPT/ALP-PIII (Fujifilm Co., Tokyo, Japan) and spectrophotometer (FUJI DRI-CHEM 3000, Fujifilm Co.), according to the manufacturer's instructions.

Histological examination and immunohistochemistry Liver samples were fixed in $10 \%$ formalin and embedded in paraffin. The sections were then cut $(5 \mu \mathrm{m})$ and stained with Sirius red to assess fibrosis. For immunohistochemical analysis, the samples were incubated with monoclonal antibody to $a$-smooth muscle actin ( $\alpha$-SMA) (1:500 dilution, Sigma).

\section{RNA isolation and quantitative polymerase chain reaction analysis}

RNA was isolated with a combination of Trizol and subsequent Qiagen RNeasy Plus Mini Kit according to the manufacturer's instructions (Qiagen, Hilden, Germany). Following reverse transcription, quantitative real-time polymerase chain reaction (qPCR) was performed on an ABI 7300 cycler using TaqMan probe sets for $\alpha$-actin-2 (Acta2), $\alpha-1$ type I collagen (Col1 a1), tissue inhibitor of metalloproteinase-1 (Timp1), transforming growth factor $\beta 1$ (Tgf $\beta 1$ ), interleukin 6 (II6), tumor necrosis factor $\alpha$ (Tnf- $\alpha$ ), and glyceraldehyde 3-phosphate dehydrogenase (GAPDH) (Applied Biosystems, Foster City, CA, USA). The expression of each gene was normalized to $G A P D H$ and fold-induction was calculated based on the $\triangle \triangle C t$ method.

\section{Western blot}

We performed electrophoresis of protein extracts using T-PER Tissue Protein Extraction Reagent (Thermo Fisher Scientific Inc., Hanover Park, IL, USA) and subsequent blotting. For Western blotting, proteins were transferred to nitrocellulose mem- 
branes using an iBLOT blotting system (Life Technologies, Seoul, Korea). We incubated blots with mouse antibody to $\alpha-$ SMA (Sigma) at a dilution of 1:500. Chemiluminscence signals were detected using SuperSignal West Pico Chemiluminescent Substrate (Thermo Fisher Scientific Inc.). Blots were reprobed with mouse antibody to $\beta$-actin (Sigma).
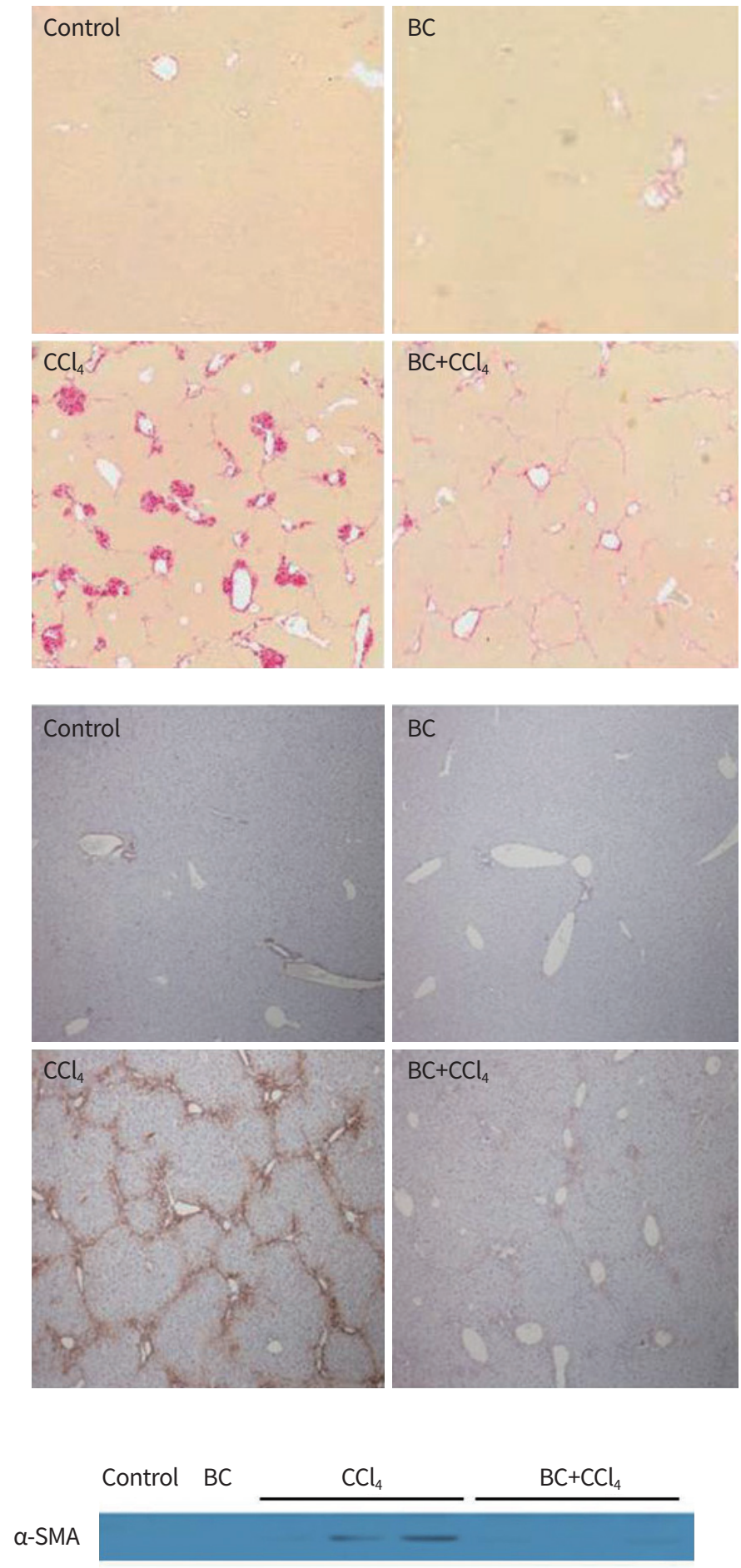

$\beta$-Actin
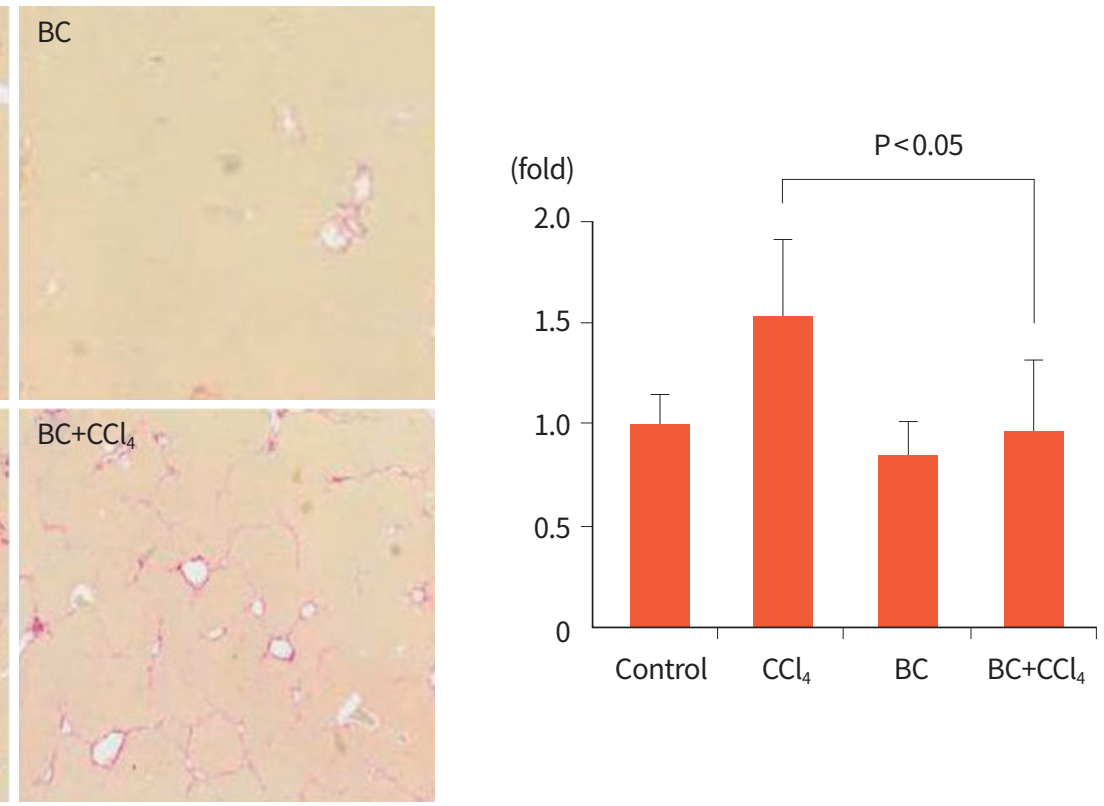

A

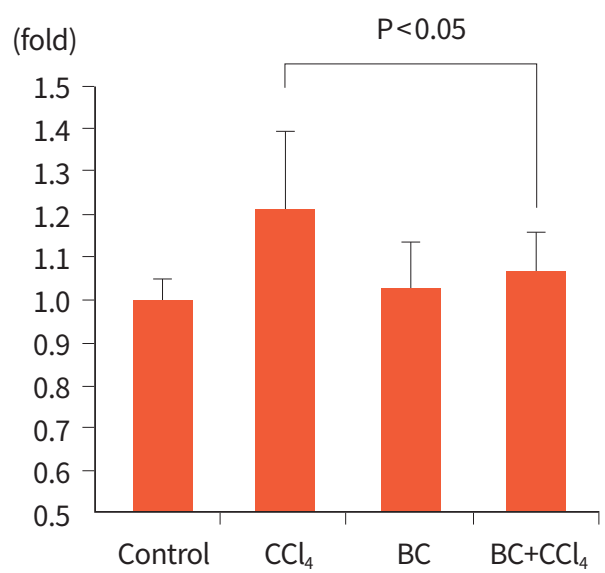

B

Fig. 1. Bovine colostrum (BC) ameliorates carbon tetrachloride $\left(\mathrm{CCl}_{4}\right)$-induced hepatic fibrosis. Male Balb/c mice were injected with corn oil or $\mathrm{CCl}_{4}$ with or without $\mathrm{BC}$ treatment. Hepatic fibrosis was evaluated using (A) Sirius red staining, (B) $\alpha$-smooth muscle actin ( $\alpha$-SMA) immunohistochemistry, and (C) $\alpha$-SMA immunoblotting. 


\section{RESULTS}

Forty 8 hours after the final $\mathrm{CCl}_{4}$ injection, the $\mathrm{CCl}_{4}$ group showed overt hepatic fibrosis induction by $53 \%$ compared to the control group, whereas the $\mathrm{BC}+\mathrm{CCl}_{4}$ group had a $55 \%$ reduction in fibrosis as demonstrated by Sirius red staining (Fig. 1A).

In the analysis of $\alpha$-SMA expression, which is a marker of activated $\mathrm{HSCs}, \mathrm{CCl}_{4}$ significantly increased $\alpha$-SMA expression levels compared to those in the control group, whereas additional BC treatment reduced $\alpha$-SMA expression to the same level as in the control group, as demonstrated by immunohistochemistry and immunoblotting (Fig. 1B, C).

We then analyzed the contribution of $\mathrm{BC}$ to the fibrogenic response of the liver. $\mathrm{CCl}_{4}$ treatment increased the expression of Acta2, Col1a1, Timp1, and Tgf $\beta 1$, which encode profibrogenic markers, and of proinflammatory cytokine genes $1 / 6$ and Tnf- $\alpha$ (Fig. 2). Compared to the $\mathrm{CCl}_{4}$ group, the $\mathrm{BC}+\mathrm{CCl}_{4}$ group showed significant 8.42-, 21.11-, 0.57-, and 2.90-fold reductions in the expression of Acta2, Col1 $\alpha 1$, Tgf $\beta 1$, and Tnf- $\alpha$, respectively $(\mathrm{P}<0.05)$ (Fig. 2). The Timp1 and $/ 16$ expression were reduced by 4.51 - and 4.33 -fold in the $\mathrm{BC}+\mathrm{CCl}_{4}$ group versus the $\mathrm{CCl}_{4}$ group, respectively; however, the differences did

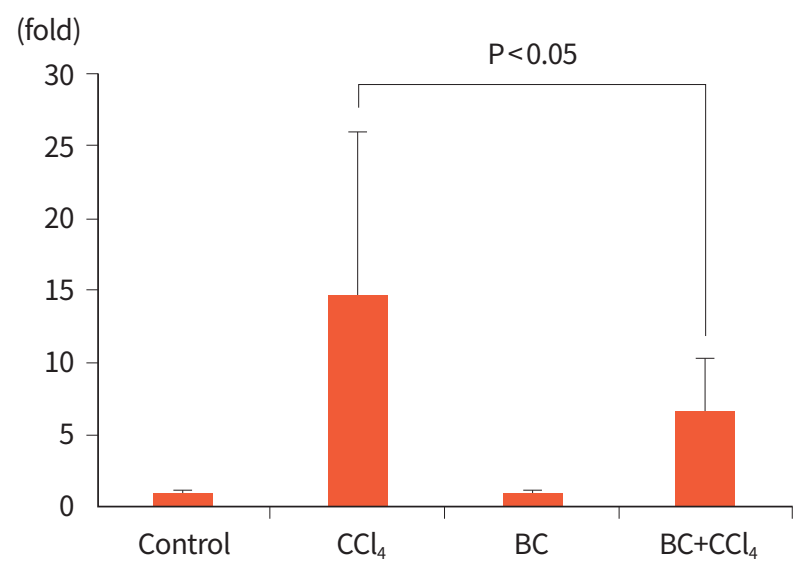

Fig. 3. Bovine colostrum (BC) inhibits hepatocellular injury. Hepatocelluar injury was determined using serum alanine aminotransferase (ALT) level. ALT level was measured using sera collected from the inferior vena cava. $\mathrm{CCl}_{4}$, carbon tetrachloride.
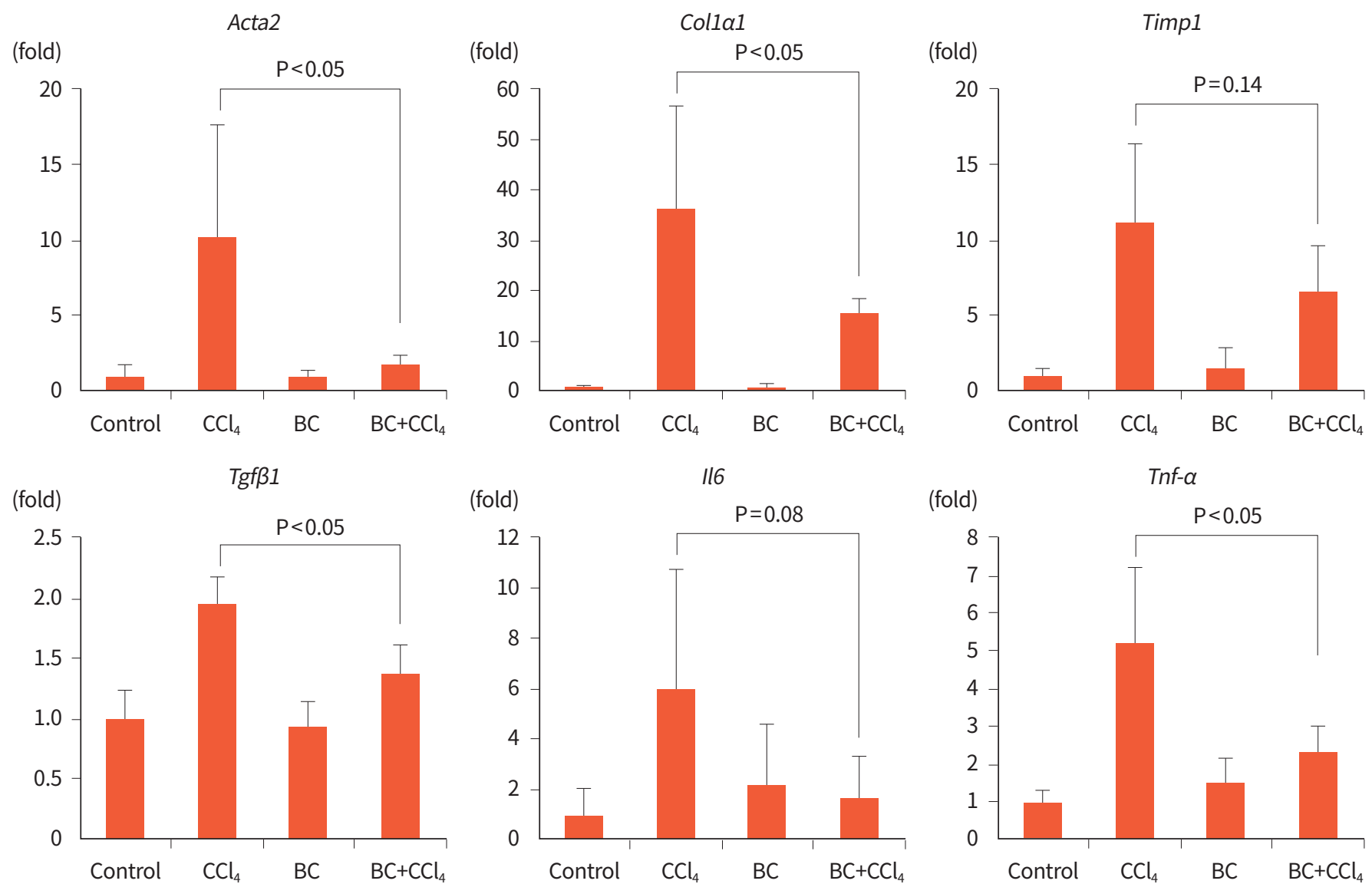

Fig. 2. Bovine colostrum (BC) inhibits fibrogenesis-related gene expression. Levels of Acta2, Col1 $\alpha 1$, Timp1, Tgf $\beta 1$, Il6, and Tnf- $\alpha$ mRNA were determined using quantitative real-time polymerase chain reaction. Gene expression is expressed as fold-induction in comparison to the control group. $\mathrm{CCl}_{4}$, carbon tetrachloride; Acta2, $\alpha$-actin-2; Col1 $\alpha 1, \alpha-1$ type I collagen; TIMP1, tissue inhibitor of metalloproteinase-1; Tgf $\beta 1$, transforming growth factor $\beta 1$; Il6, interleukin $6 ;$ Tnf- $\alpha$, tumor necrosis factor $\alpha$. 
not reach statistical significance.

We also found a significant reduction in hepatocellular injury as determined by serum ALT levels in the $\mathrm{BC}+\mathrm{CCl}_{4}$ group compared to the $\mathrm{CCl}_{4}$ group (Fig. 3).

\section{DISCUSSION}

Oxidative stress is a major factor contributing to the onset of hepatic fibrosis in various liver diseases, including chronic HBV infection and long-term alcohol consumption [16]. ROS are generated mainly via the mitochondrial electron transport chain or via activation of cytochrome P450, mostly cytochrome P450 2E1, nicotinamide adenine dinucleotide phosphate oxidase, or xanthine oxidase or mitochondrial damage. ROS generation in HSC and myofibroblasts occurs in response to several known profibrogenic mediators, including angiotensin II, platelet-derived growth factor, TGF $\beta$, and leptin [20], and the generated ROS up-regulate the expression of critical fibrosis-related genes such as COL1A1, COL1A2, monocyte chemoattractant protein-1 (MCP1), and TIMP1 via activation of signal transduction pathways and transcription factors, including c-Jun N-terminal kinase, activator protein-1, and nuclear factor-kB [1]. Oxidative stress also alters mitochondrial permeability, which leads to the promotion of hepatocyte necrosis and/or apoptosis. Furthermore, hepatocarcinogenesis in the cirrhotic liver is associated with severe oxidative stress [21].

In an experimental setting, $\mathrm{CCl}_{4}$ induces hepatic fibrosis via the formation of free radicals, ROS, and lipid peroxidation products [17]. $\mathrm{CCl}_{4}$ is metabolized into trichloromethyl $\left(-\mathrm{CCl}_{3}\right)$ and trichloromethyl peroxyl $(-\mathrm{OOCCl})$ by cytochrome $\mathrm{P} 450$ enzymes in the liver, and generates free radicals in the process. These free radicals are responsible for oxidative stressinduced hepatic damage and fibrosis [22]. Thus, the $\mathrm{CCl}_{4}$-induced fibrosis model is widely used to evaluate the hepatoprotective effects of various pharmacological therapies. Previous reports have demonstrated that several antioxidant drugs can attenuate $\mathrm{CCl}_{4}$-induced hepatotoxicity $[23,24]$. The administration of $\mathrm{N}$-acetylcysteine decreases liver fibrosis by increasing glutathione (GSH) level and decreasing the expression of induced nitric oxide synthase (iNOS) [23]. Moreover, treatment with insulin-like growth factor-I reduced myeloperoxidase level and the expression of iNOS in $\mathrm{CCl}_{4}$ model rats [24]. In the present study, we investigated the preventive effect of $\mathrm{BC}$ on hepatic fibrosis induced by $\mathrm{CCl}_{4}$. $\mathrm{BC}$ dramatically ameliorated $\mathrm{CCl}_{4}$-induced hepatic fibrosis by inhibiting fibrogenesis-related gene expression and also decreased $\mathrm{CCl}_{4}{ }^{-}$ induced hepatic injury.

To date, many studies have demonstrated the protective effect of breast milk against various infectious diseases in infants, including respiratory infections, diarrhea, otitis media, and infections in premature infants $[25,26]$. In addition to the numerous clinically significant benefits of breastfeeding, breastmilk also has bioactive components that protect newborns from hyperoxic challenge due to transition of life to an environment far richer in oxygen than the intrauterine environment $[27,28]$. It is believed that oxidative stress is involved in the pathogenesis of numerous neonatal diseases such as bronchopulmonary dysplasia, retinopathy of prematurity and necrotizing enterocolitis [29,30]. Breast milk has a number of enzymatic and non-enzymatic antioxidant constituents, including superoxide dismutase, GSH peroxidase, catalase, vitamin $\mathrm{E}$, vitamin $\mathrm{C}$, and $\beta$-carotene, which protect newborns against ROS in the early stage of life [29,31]. Accordingly, previous studies have demonstrated the high antioxidant capacity and radical scavenging activity of colostrum. Zarban et al. [14] measured total antioxidant capacity (TAC) and free radical scavenging activity in human milk during the first 6 months of lactation. Both TAC and free radical scavenging activity were significantly higher in colostrum than transitional and mature milk. Quiles et al. [15] also showed that the TAC of milk was significantly higher in colostrum compared with mature and transitional milk. Thus, colostrum might be therapeutically useful for various pathologic conditions in which oxidative stress is involved in the pathogenesis.

In summary, the present study demonstrated that colostrum can ameliorate $\mathrm{CCl}_{4}$-induced hepatic fibrosis by inhibiting fibrogenesis-related gene expression and also decreases $\mathrm{CCl}_{4}$-induced hepatic injury. Therefore, colostrum might be therapeutically efficacious in preventing hepatic fibrosis in a variety of human liver diseases.

\section{CONFLICTS OF INTEREST}

No potential conflict of interest relevant to this article was reported.

\section{ACKNOWLEDGMENTS}

This research was supported by the Basic Science Research Program through the National Research Foundation of Korea (NRF) funded by the Ministry of Science, ICT \& Future Planning (grant number: 2012R1A1A3010961). 


\section{ORCID}

Geum-Youn Gwak https://orcid.org/0000-0002-6453-3450

\section{REFERENCES}

1. Bataller R, Brenner DA. Liver fibrosis. J Clin Invest 2005; 115:209-18.

2. Povero D, Busletta C, Novo E, di Bonzo LV, Cannito S, Paternostro C, et al. Liver fibrosis: a dynamic and potentially reversible process. Histol Histopathol 2010;25:1075-91.

3. Svegliati Baroni G, D’Ambrosio L, Ferretti G, Casini A, Di Sario A, Salzano R, et al. Fibrogenic effect of oxidative stress on rat hepatic stellate cells. Hepatology 1998;27:720-6.

4. Hellerbrand C, Stefanovic B, Giordano F, Burchardt ER, Brenner DA. The role of TGFbeta1 in initiating hepatic stellate cell activation in vivo. J Hepatol 1999;30:77-87.

5. Tsukamoto $\mathrm{H}$. Is interleukin-10 antifibrogenic in chronic liver injury? Hepatology 1998;28:1707-9.

6. Knittel T, Janneck T, Muller L, Fellmer P, Ramadori G. Transforming growth factor beta 1-regulated gene expression of Ito cells. Hepatology 1996;24:352-60.

7. Pinzani M, Milani S, Grappone C, Weber FL Jr, Gentilini P, Abboud HE. Expression of platelet-derived growth factor in a model of acute liver injury. Hepatology 1994;19:701-7.

8. Lasky JA, Ortiz LA, Tonthat B, Hoyle GW, Corti M, Athas G, et al. Connective tissue growth factor mRNA expression is upregulated in bleomycin-induced lung fibrosis. Am J Physiol 1998;275(2 Pt 1):L365-71.

9. Abraham DJ, Shiwen X, Black CM, Sa S, Xu Y, Leask A. Tumor necrosis factor alpha suppresses the induction of connective tissue growth factor by transforming growth factor-beta in normal and scleroderma fibroblasts. J Biol Chem 2000;275:15220-5.

10. Mero A, Miikkulainen H, Riski J, Pakkanen R, Aalto J, Takala T. Effects of bovine colostrum supplementation on serum IGF-I, IgG, hormone, and saliva IgA during training. J Appl Physiol (1985) 1997;83:1144-51.

11. Severin S, Wenshui X. Milk biologically active components as nutraceuticals: review. Crit Rev Food Sci Nutr 2005;45: 645-56.

12. Buescher ES, McWilliams-Koeppen P. Soluble tumor necrosis factor-alpha (TNF-alpha) receptors in human colostrum and milk bind to TNF-alpha and neutralize TNFalpha bioactivity. Pediatr Res 1998;44:37-42.

13. Garofalo RP, Goldman AS. Cytokines, chemokines, and colony-stimulating factors in human milk: the 1997 up- date. Biol Neonate 1998;74:134-42.

14. Zarban A, Taheri F, Chahkandi T, Sharifzadeh G, Khorashadizadeh M. Antioxidant and radical scavenging activity of human colostrum, transitional and mature milk. J Clin Biochem Nutr 2009;45:150-4.

15. Quiles JL, Ochoa JJ, Ramirez-Tortosa MC, Linde J, Bompadre S, Battino M, et al. Coenzyme Q concentration and total antioxidant capacity of human milk at different stages of lactation in mothers of preterm and full-term infants. Free Radic Res 2006;40:199-206.

16. Muriel P. Role of free radicals in liver diseases. Hepatol Int 2009;3:526-36.

17. Weber LW, Boll M, Stampfl A. Hepatotoxicity and mechanism of action of haloalkanes: carbon tetrachloride as a toxicological model. Crit Rev Toxicol 2003;33:105-36.

18. Pierce RA, Glaug MR, Greco RS, Mackenzie JW, Boyd CD, Deak SB. Increased procollagen mRNA levels in carbon tetrachloride-induced liver fibrosis in rats. J Biol Chem 1987;262:1652-8.

19. Hernandez-Munoz R, Diaz-Munoz M, Suarez J, Chagoya de Sanchez V. Adenosine partially prevents cirrhosis induced by carbon tetrachloride in rats. Hepatology 1990; 12:242-8.

20. De Minicis S, Bataller R, Brenner DA. NADPH oxidase in the liver: defensive, offensive, or fibrogenic? Gastroenterology 2006;131:272-5.

21. Shimamoto K, Hayashi H, Taniai E, Morita R, Imaoka M, Ishii Y, et al. Antioxidant N-acetyl-L-cysteine (NAC) supplementation reduces reactive oxygen species (ROS)-mediated hepatocellular tumor promotion of indole-3-carbinol (I3C) in rats. J Toxicol Sci 2011;36:775-86.

22. Jimenez W, Claria J, Arroyo V, Rodes J. Carbon tetrachloride induced cirrhosis in rats: a useful tool for investigating the pathogenesis of ascites in chronic liver disease. $J$ Gastroenterol Hepatol 1992;7:90-7.

23. Pereira-Filho G, Ferreira C, Schwengber A, Marroni C, Zettler $\mathrm{C}$, Marroni $\mathrm{N}$. Role of $\mathrm{N}$-acetylcysteine on fibrosis and oxidative stress in cirrhotic rats. Arq Gastroenterol 2008;45: 156-62.

24. Garcia-Fernandez M, Castilla-Cortazar I, Diaz-Sanchez M, Navarro I, Puche JE, Castilla A, et al. Antioxidant effects of insulin-like growth factor-I (IGF-I) in rats with advanced liver cirrhosis. BMC Gastroenterol 2005;5:7.

25. Lonnerdal B. Breast milk: a truly functional food. Nutrition 2000;16:509-11.

26. Lawrence RM, Pane CA. Human breast milk: current concepts of immunology and infectious diseases. Curr Probl 
PRECISION AND FUTURE MEDICINE

Anti-fibrotic effect of bovine colostrum

Pediatr Adolesc Health Care 2007;37:7-36.

27. Saugstad OD. Bronchopulmonary dysplasia-oxidative stress and antioxidants. Semin Neonatol 2003;8:39-49.

28. Friel JK, Friesen RW, Harding SV, Roberts LJ. Evidence of oxidative stress in full-term healthy infants. Pediatr Res 2004;56:878-82.

29. Scheibmeir HD, Christensen K, Whitaker SH, Jegaethesan J, Clancy R, Pierce JD. A review of free radicals and antioxidants for critical care nurses. Intensive Crit Care Nurs
2005;21:24-8.

30. Thompson AM, Bizzarro MJ. Necrotizing enterocolitis in newborns: pathogenesis, prevention and management. Drugs 2008;68:1227-38.

31. L'Abbe MR, Friel JK. Superoxide dismutase and glutathione peroxidase content of human milk from mothers of premature and full-term infants during the first 3 months of lactation. J Pediatr Gastroenterol Nutr 2000;31:270-4. 